\title{
РОЛЬ НАЛОГА НА ДОХОДЫ ФИЗИЧЕСКИХ ЛИЦ В ДОХОДАХ БЮДЖЕТНОЙ СИСТЕМЫ РЕГИОНОВ В УСЛОВИЯХ КРИЗИСА
}

\begin{abstract}
Аннотация. Предметом исследования является рассмотрение значимости налога на доходы физических лии в качестве одного из бюджетообразующих доходных источников консолидированных бюджетов субъектов федерации Центрального федерального округа. Проводиться сравнение данного источника дохода бюджетов регионов с другими источниками их доходов. Отмечается что налог на доходы физических лии является основным источником доходов бюджетных систем регионов. Как следствие основной упор в статье автор делает на факторах, оказываюшие позитивное влияние на его поступление в субъектах ЦФО. Методология исследования включает проведение сравнительного анализа и логической интерпретации полученных результатов, сформулированных в виде обобщающих выводов. К числу основных положений, отражающих результаты проведенного анализа относятся следующие: раскрыты особенности поступления НДФЛ в бюджетную систему регионов ЦФО; сделан вывод о сокращении поступлений по налогу для большинства субъектов ЦФО, что отражается на снижении доходов бюджетной системы регионов; отмечена корреляция сумм поступления НДФЛ в бюджет субъекта РФ в зависимости от сложившегося уровня заработной платы в регионах; выявлены различия в уровне поступления НДФЛ на душу населения в субъектах ЦФО.

Ключевые слова: НДФЛ, бюджетная система региона, консолидированный бюджет субъекта, уровень доходов, номинальная заработная плата, численность населения, экономически активное население, вариация доходов, трудовая миграчия, региональная экономика.
\end{abstract}

Abstract. The subject of the research is the personal income tax as one of the budget revenue generating sources of consolidated budgets in Central Federal District's constituents. The author compares this source of regional budget revenues to other sources. Zhuravleva underlines that personal income tax is the main source of the regional budget revenues. As a consequence, the resaercher focuses on the factors that have a positive influence on the payment of personal income tax in the Central Federal District. The research methodology includes comparative analysis and logical interpretation of the results in the form of generalizations. The basic provisions regarding the results of the analysis carried out are the following: the author of the article has described the main peculiarities of personal income tax as the source of the regional budget revenues in the Central Federal District; made a conclusion about reduction of these revenues for the majority of the Central Federal District's constituents which lowers the volume of regional budget revenues in general; noted the correlation between the sums of personal income tax in the Russian Federation constituent's budget and the wage levels in regions; defined differences in the level of personal income tax revenues per capita in the Central Federal District's constituents.

Keywords: personal income tax, regional budget system, consolidated budget of a constituent, income level, nominal (gross) wage, population, economically active population, variation in income, labor migration, regional economy.

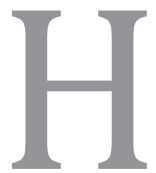
алог на доходы физических лиц - это один из наиболее значимых налогов для такой группы налогоплательщиков, как физические лица. Но, с другой стороны, рассмотрение данного налога крайне важно в качестве источника доходов консолидированного бюджета субъектов Российской Федерации. Данный налог, являясь федеральным налогом в налоговой системе РФ, формирует значительную долю доходов консолидированных бюджетов субъектов Российской Федерации. [1]
В статье 56 Бюджетного кодекса РФ указывается, что 85\% поступлений налога на администрируемой территории субъекта направляется в бюджет субъекта РФ, а оставшиеся $15 \%$ согласно ст. 61, ст. 61.1, 61.2, 61.3, 61.5 делятся между местными бюджетами территорий.[2]

Данный налог среди общего объема доходов консолидированных бюджетов России занимал от 8,3\% (2000г.) до 8,4\% (2008г.), а среди налоговых доходов он обеспечивал от 10,2\% (2000г.) до 19,5\% (2008г.), что позволяет констатировать 


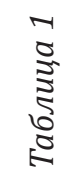

\begin{tabular}{|c|c|c|c|c|c|c|c|c|c|c|c|c|c|}
\hline \multirow{7}{*}{\multicolumn{2}{|c|}{\begin{tabular}{|} 
\\
\\
\\
\\
\multirow{2}{*}{} \\
\multirow{2}{*}{}
\end{tabular}}} & & $\exists$ & Ln & $\begin{array}{l}n \\
0 \\
i\end{array}$ & $\begin{array}{l}\text { Ln } \\
\sigma^{0} \\
7\end{array}$ & $\stackrel{ }{\stackrel{7}{7}}$ & $\stackrel{⿱}{i}$ & $\begin{array}{l}0 \\
\text { is } \\
\rightarrow\end{array}$ & $\vec{i}$ & $\underset{m}{m}$ & $\stackrel{F}{F}$ & $\stackrel{m}{+}$ \\
\hline & & 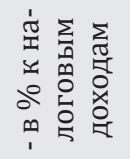 & 욱 & $\overrightarrow{\mathrm{N}}$ & $\hat{\vec{m}}$ & 离 & $\overrightarrow{\dot{m}}$ & $\begin{array}{l}\stackrel{\infty}{-} \\
\text { sim }\end{array}$ & $\begin{array}{l}\text { 노 } \\
\text { Ln }\end{array}$ & $\begin{array}{l}\text { 노 } \\
\stackrel{\text { L }}{N}\end{array}$ & $\overrightarrow{\text { s. }}$ & $\overrightarrow{\text { sे }}$ & $\stackrel{\widetilde{m}}{\text { f }}$ \\
\hline & & 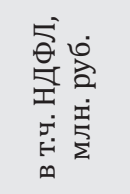 & $a$ & $\begin{array}{l}0 \\
0 \\
0 \\
\infty \\
0 \\
\llcorner \\
0 \\
-1\end{array}$ & 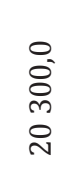 & $\begin{array}{l}\text { m } \\
\text { L } \\
\text { ڤN } \\
\text { - }\end{array}$ & 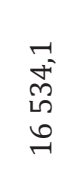 & 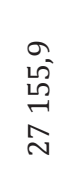 & $\begin{array}{l}\sigma \\
\vec{N} \\
\stackrel{N}{\sigma} \\
\sigma\end{array}$ & 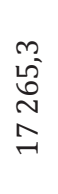 & $\begin{array}{l}\text { Ln } \\
\text { Oे } \\
\text { Oे } \\
\text { r. }\end{array}$ & $\begin{array}{l}\underset{N}{\tilde{N}} \\
\stackrel{\sim}{\sim} \\
\underset{\sim}{\sim}\end{array}$ & 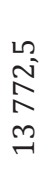 \\
\hline & & 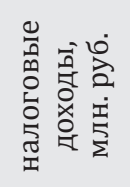 & $\infty$ & 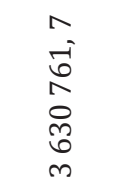 & 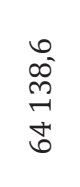 & $\begin{array}{l}\circ \\
\stackrel{2}{1} \\
\dot{m}\end{array}$ & 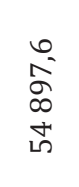 & $\begin{array}{l}\underset{N}{N} \\
\mathbb{N} \\
\stackrel{N}{N}\end{array}$ & 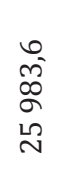 & 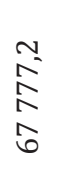 & $\begin{array}{l}\text { m. } \\
\text { مे } \\
\hat{0} \\
\text { مे }\end{array}$ & \begin{tabular}{l}
$\hat{a}$ \\
o) \\
\multirow{+}{*}{} \\
qे
\end{tabular} & $\begin{array}{l}\infty \\
\stackrel{+}{+} \\
\hat{i} \\
\dot{m}\end{array}$ \\
\hline & & 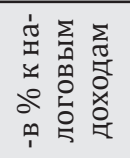 & $\wedge$ & $\stackrel{+}{\infty}$ & $\stackrel{\vec{\sigma}}{\sigma}$ & $\begin{array}{l}\vec{m} \\
\vec{m}\end{array}$ & 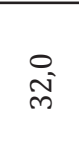 & $\begin{array}{l}\infty \\
\text { ஸे }\end{array}$ & $\begin{array}{l}\infty \\
\text { L }^{-}\end{array}$ & $\stackrel{\infty}{\stackrel{\infty}{N}}$ & $\underset{m}{\vec{m}}$ & $\begin{array}{l}\stackrel{0}{ } \\
\stackrel{\infty}{\sim}\end{array}$ & $\stackrel{F}{\stackrel{f}{f}}$ \\
\hline & & 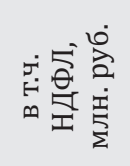 & 0 & \begin{tabular}{l}
$\hat{y}$ \\
$\hat{b}$ \\
\multirow{+}{*}{} \\
$\stackrel{0}{0}$ \\
$\delta$
\end{tabular} & $\begin{array}{l}0 \\
\substack{N \\
N \\
\infty \\
\sim \\
\sim}\end{array}$ & $\begin{array}{l}\stackrel{N}{\infty} \\
\infty \\
\tilde{m} \\
0 \\
0\end{array}$ & 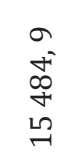 & \begin{tabular}{l}
$\sigma$ \\
\multirow{+}{*}{} \\
$\infty$ \\
\multirow{N}{N}{}
\end{tabular} & 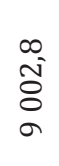 & 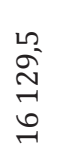 & $\begin{array}{l}\sigma \\
\text { ô } \\
D^{\circ} \\
0\end{array}$ & $\begin{array}{l}\overrightarrow{1} \\
\text { जे } \\
\text { mे } \\
\vec{\Rightarrow}\end{array}$ & $\begin{array}{l}m \\
- \\
\infty \\
m \\
m\end{array}$ \\
\hline & & 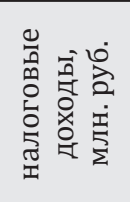 & Ln & $\begin{array}{l}0 \\
\infty \\
0 \\
10 \\
10 \\
0 \\
0 \\
0 \\
m\end{array}$ & 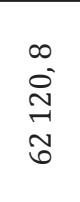 & $\begin{array}{l}\stackrel{+}{o} \\
\infty \\
m \\
m \\
m\end{array}$ & $\begin{array}{l}\vec{I} \\
\underset{\pi}{\pi} \\
\infty \\
\infty\end{array}$ & \begin{tabular}{l}
0 \\
0 \\
\multirow{2}{+}{} \\
\multirow{1}{*}{} \\
\end{tabular} & 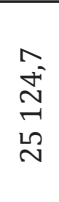 & $\begin{array}{l}\text { m } \\
\text { N } \\
\text { D } \\
\infty \\
i n\end{array}$ & $\begin{array}{l}+ \\
\infty \\
\infty \\
\sigma \\
\sigma \\
\sigma\end{array}$ & 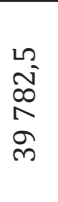 & 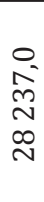 \\
\hline & & 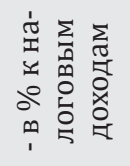 & + & $\begin{array}{l}0 \\
\infty^{0} \\
m^{\circ}\end{array}$ & $\begin{array}{l}\vec{m} \\
\vec{m}\end{array}$ & $\overrightarrow{\vec{H}}$ & $\stackrel{\stackrel{\sim}{*}}{\stackrel{f}{*}}$ & $\stackrel{\sim}{\tilde{y}}$ & $\begin{array}{l}\text { 노 } \\
\text { ㅇ. }\end{array}$ & $\begin{array}{l}0 \\
\mathscr{\sigma}^{0}\end{array}$ & $\begin{array}{l}\stackrel{+}{6} \\
\dot{q}\end{array}$ & $\stackrel{\stackrel{N}{+}}{\text { mे }}$ & : \\
\hline & $\begin{array}{l}\infty \\
\stackrel{\sim}{\sim} \\
\end{array}$ & 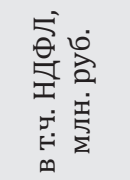 & $m$ & \begin{tabular}{l}
+ \\
0 \\
ర్ \\
0 \\
\multirow{0}{0}{}
\end{tabular} & 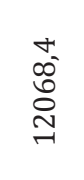 & $\begin{array}{l}\infty \\
\emptyset^{-} \\
\infty \\
\infty\end{array}$ & 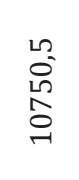 & 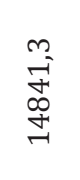 & $\begin{array}{l}m \\
\text { oे } \\
\tilde{m} \\
0\end{array}$ & $\begin{array}{l}+ \\
\dot{a} \\
\dot{a}\end{array}$ & $\begin{array}{l}0 \\
0 \\
\infty \\
\infty \\
\infty \\
+\end{array}$ & \begin{tabular}{l}
\multirow{2}{*}{} \\
$\stackrel{N}{N}$
\end{tabular} & 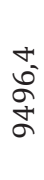 \\
\hline & & 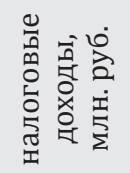 & $\sim$ & $\begin{array}{l}02 \\
0 \\
\stackrel{1}{0} \\
\overrightarrow{0} \\
0 \\
-1\end{array}$ & 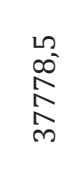 & $\begin{array}{l}\stackrel{\sigma}{\overrightarrow{0}} \\
\overrightarrow{0} \\
\vec{m} \\
\rightarrow\end{array}$ & $\begin{array}{l}\text { à } \\
\text { d } \\
\stackrel{\text { N }}{\text { N }}\end{array}$ & 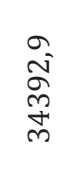 & 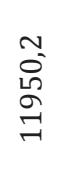 & 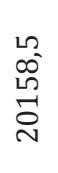 & 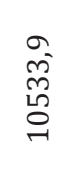 & $\begin{array}{l}\vec{\sigma} \\
\stackrel{5}{\circ} \\
\vec{\sim}\end{array}$ & 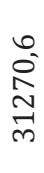 \\
\hline & & & $r$ & 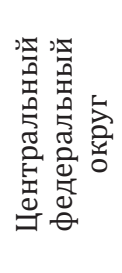 & 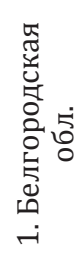 & 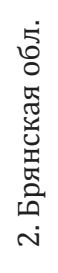 & 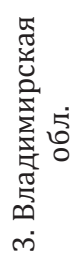 & 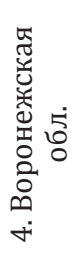 & 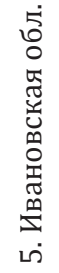 & 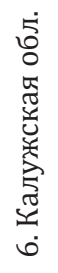 & 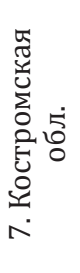 & 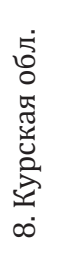 & 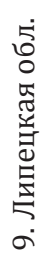 \\
\hline
\end{tabular}




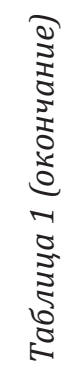

\begin{tabular}{|c|c|c|c|c|c|c|c|c|c|c|c|c|}
\hline \multirow{7}{*}{\multicolumn{2}{|c|}{ }} & & $\exists$ & 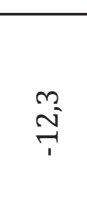 & $\stackrel{\circ}{i}$ & 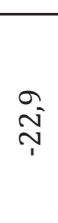 & $\begin{array}{l}m \\
\sigma_{7}^{2}\end{array}$ & $\begin{array}{l}\text { Ln } \\
\text { ب̂ }\end{array}$ & $\begin{array}{l}\stackrel{0}{1} \\
\stackrel{n}{7}\end{array}$ & $\stackrel{7}{i}$ & $\begin{array}{l}\infty \\
\stackrel{\infty}{N} \\
\stackrel{1}{N}\end{array}$ & $\stackrel{\infty}{\uparrow}$ \\
\hline & & 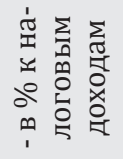 & $\stackrel{ }{\circ}$ & $\begin{array}{l}\stackrel{L}{ } \\
\stackrel{\infty}{\sim}\end{array}$ & $\begin{array}{l}\stackrel{L}{2} \\
\text { }\end{array}$ & $\stackrel{\widehat{\infty}}{\stackrel{\sim}{\sim}}$ & $\begin{array}{c}m \\
\stackrel{m}{N}\end{array}$ & 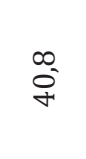 & $\hat{\tilde{m}}$ & $\stackrel{\vec{m}}{\vec{m}}$ & $\overrightarrow{5}$ & $\begin{array}{l}m \\
\stackrel{n}{N}\end{array}$ \\
\hline & & 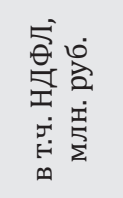 & $a$ & 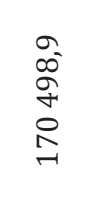 & $\begin{array}{l}\sigma \\
\overrightarrow{-} \\
\underset{\infty}{\infty} \\
\infty\end{array}$ & $\begin{array}{l}m \\
\stackrel{m}{0} \\
\stackrel{0}{+} \\
\stackrel{+}{+}\end{array}$ & $\begin{array}{l}\infty \\
\infty \\
\infty \\
\stackrel{\infty}{N} \\
\exists\end{array}$ & $\begin{array}{l}\overrightarrow{1} \\
\overrightarrow{-} \\
\infty \\
\sigma\end{array}$ & $\begin{array}{l}\infty \\
\infty \\
\infty \\
\infty \\
\infty \\
0 \\
\sim\end{array}$ & 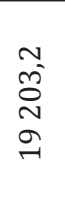 & 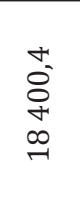 & 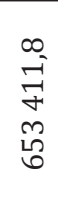 \\
\hline & & 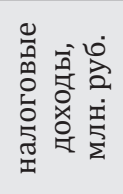 & $\infty$ & 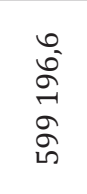 & 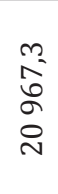 & 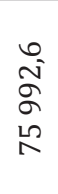 & \begin{tabular}{l}
$\infty$ \\
Is \\
\multirow{\infty}{*}{} \\
mे
\end{tabular} & $\begin{array}{l}\text { ñ } \\
\text { Jे } \\
\stackrel{+}{+} \\
\stackrel{\sim}{N}\end{array}$ & $\begin{array}{l}0 \\
\text { oे } \\
\text { ஸे } \\
\text { हn }\end{array}$ & $\begin{array}{l}\infty \\
\text { N } \\
\stackrel{2}{a} \\
\vec{b}\end{array}$ & $\begin{array}{l}\mathfrak{N} \\
- \\
\vdots \\
0 \\
0 \\
-1\end{array}$ & 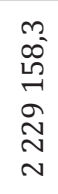 \\
\hline & & 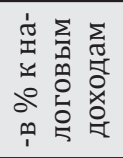 & $\wedge$ & $\stackrel{\vec{\infty}}{\stackrel{-1}{N}}$ & $\begin{array}{l}n \\
\rho^{2}\end{array}$ & $\stackrel{\stackrel{\llcorner}{+}}{\underset{+}{\sim}}$ & $\begin{array}{l}\stackrel{1}{N} \\
\stackrel{m}{n}\end{array}$ & $\stackrel{\llcorner}{\stackrel{2}{+}}$ & $\stackrel{\stackrel{\llcorner}{+}}{\stackrel{m}{m}}$ & $\begin{array}{l}\stackrel{0}{\infty} \\
\infty_{m}^{0}\end{array}$ & 욱 & $\overrightarrow{\mathbb{N}^{-}}$ \\
\hline & & 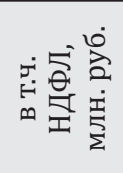 & 0 & $\begin{array}{l}n \\
\infty \\
\infty \\
n \\
n \\
n \\
n \\
n\end{array}$ & $\begin{array}{l}0 \\
0 \\
1 \\
\infty \\
\infty\end{array}$ & $\begin{array}{l}m \\
\sim \\
0 \\
0 \\
m \\
m\end{array}$ & 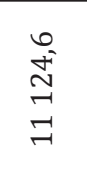 & $\begin{array}{l}M^{m} \\
\sigma^{2} \\
0 \\
\infty \\
\infty\end{array}$ & 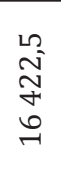 & $\begin{array}{l}\stackrel{+}{+} \\
\stackrel{+}{W} \\
\stackrel{-}{\sigma}\end{array}$ & $\begin{array}{l}\stackrel{N}{N} \\
\text { İ } \\
\text { I }\end{array}$ & 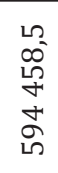 \\
\hline & & 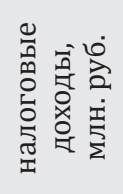 & เ & 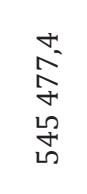 & \begin{tabular}{l}
0 \\
$\stackrel{1}{1}$ \\
$\infty$ \\
$\infty$ \\
\multirow{1}{+}{} \\
$\stackrel{1}{1}$
\end{tabular} & $\begin{array}{l}\hat{\text { aे }} \\
\text { o } \\
\text { o }\end{array}$ & $\begin{array}{l}0 \\
\stackrel{N}{N} \\
\text { के }\end{array}$ & 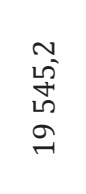 & $\begin{array}{l}\text { Fे } \\
\text { Hુ } \\
\text { f }\end{array}$ & 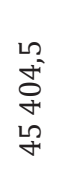 & 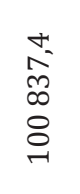 & 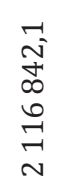 \\
\hline & & 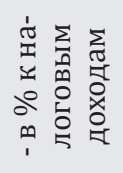 & $\sigma$ & $\begin{array}{l}\infty \\
\stackrel{q}{+}^{-}\end{array}$ & 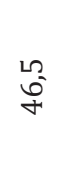 & $\stackrel{0}{\rightarrow}$ & $\stackrel{\circ}{\stackrel{0}{\&}}$ & $\stackrel{m}{\stackrel{m}{*}}$ & $\begin{array}{l}m \\
\cos ^{0}\end{array}$ & $\begin{array}{l}\stackrel{L^{2}}{\infty_{m}^{\circ}} \\
\stackrel{n}{2}\end{array}$ & $\stackrel{\sigma}{\hat{f}}$ & $\vec{m}$ \\
\hline & 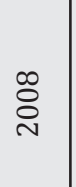 & 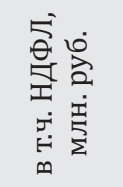 & $m$ & \begin{tabular}{l}
\multirow{H}{n}{} \\
L్ర \\
$\stackrel{N}{\alpha}$
\end{tabular} & 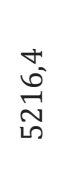 & 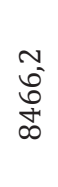 & $\begin{array}{l}0 \\
\infty \\
\infty \\
\mathbb{N} \\
N\end{array}$ & 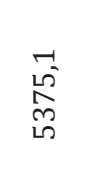 & 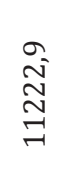 & 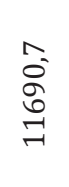 & 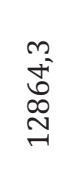 & 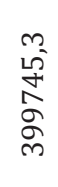 \\
\hline & & 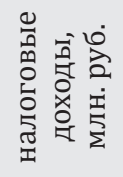 & $N$ & $\begin{array}{l}\text { Ñ } \\
\hat{0} \\
\stackrel{0}{\infty} \\
\text { N }\end{array}$ & 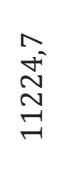 & $\begin{array}{l}\vec{c} \\
\stackrel{0}{0} \\
\stackrel{m}{\tilde{N}} \\
\end{array}$ & $\begin{array}{l}0 \\
\stackrel{D}{0} \\
\stackrel{n}{n} \\
\text { W }\end{array}$ & $\begin{array}{l}0 \\
\stackrel{0}{1} \\
\stackrel{2}{n} \\
\stackrel{7}{7}\end{array}$ & 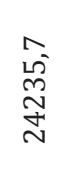 & 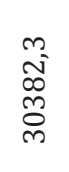 & 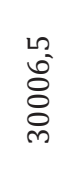 & $\begin{array}{l}-1 \\
\text { N } \\
0 \\
0 \\
\hat{0} \\
\hat{0} \\
-1\end{array}$ \\
\hline & 迹 & & $r$ & 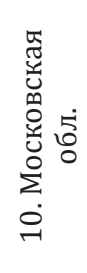 & 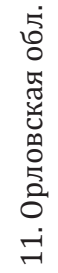 & 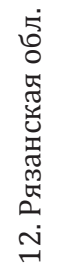 & 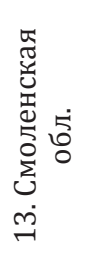 & 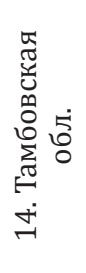 & 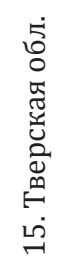 & 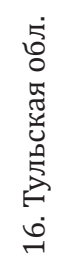 & 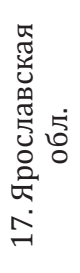 & 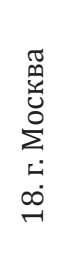 \\
\hline
\end{tabular}




\section{Налоги и налогообложение 3(141) • 2016}

его ведущие позиции как доходного источника региональных бюджетов в России. [3,С.8-9]

Рассматривая значение НДФЛ для налогоплательщиков этого налога,следует отметить, что посредством данного налога чистый доход(доход после уплаты НДФЛ) в распоряжении физических лиц снижается, что является причиной ухудшения благосостояния работающих граждан. Но, с другой стороны, посредством данного налога пополняются налоговые доходы региональных бюджетов, что позволяет органам власти регионов исполнять взятые на себя расходные обязательства.

Для подтверждения отмеченных фактов проведем анализ доходных источников консолидированных бюджетов субъектов Центрального федерального округа, уделив пристальное внимание НДФЛ.

Согласно представленных данных таблицы 1, можно отметить, что удельный вес НДФЛ в налоговых доходах консолидированного бюджета субъектов ЦФО составлял в кризисном 2008 году от 30,4\% (Липецкая область) до 50,5\% (Ивановская область).

Однако, в 2014 году доля налога на доходы физических лиц в налоговых доходах консолидированных бюджетов Центрального федерального округа снизилась к уровню 2008 года, когда по- казатели сопоставляемого периода были далеко не лучшими вследствие проявления влияния мирового финансового кризиса на экономику России:

- $\quad$ по Центральному федеральному округу в целом - на 9,5\%,

- $\quad$ а по 17 регионам ЦФО - от 0,2\% (Белгородская область) до 25,8\% (Ярославская область).

Повышение удельного веса НДФЛ в налоговых доходах консолидированного бюджета на 4,5\% в 2014 году к 2008 году произошло только в Липецкой области.

Учитывая, что НДФЛ является одним из главных доходных источников региональных бюджетов ЦФО, то условно по относительной величине поступлений данного налога в бюджетную казну регионов в 2014 году, можно разделить исследуемые регионы на 3 кластера, представленные в таблице 2.

Анализ представленных данныхпо удельному весу НДФЛ в налоговых доходах консолидированных бюджетов ЦФО в 2014 году, подтверждает наши выводы о том, что регионы действительно не могут обойтись без данного доходного источника, т.к. в 12 субъектах ЦФО из 18 значение данного показателя превышает 30\% и более, что означает тот, факт, что в настоящее время

Таблица 2

Кластеры, обусловленные удельным весом НДФЛ в налоговых доходах субъектов ЦФО в 2014 году

\begin{tabular}{|l|l|c|}
\hline \multicolumn{1}{|c|}{ Диапазон кластера } & \multicolumn{1}{|c|}{ Субъекты ЦФО } & $\begin{array}{c}\text { Количество регионов } \\
\text { в кластере }\end{array}$ \\
\hline $\begin{array}{l}\text { - до 20\% в налоговых доходах } \\
\text { консолидированного бюджета ЦФО }\end{array}$ & $\begin{array}{l}\text { Рязанская обл. (18,7\%), } \\
\text { Ярославская обл. (17,1\%) }\end{array}$ & 2 \\
\hline $\begin{array}{l}\text { - от 20 до 30\% в налоговых доходах } \\
\text { консолидированного бюджета ЦФО }\end{array}$ & $\begin{array}{l}\text { Калужская обл. (25,5\%), } \\
\text { Смоленская обл. (28,3\%), } \\
\text { Госковская обл. (28,5\%), }\end{array}$ & 4 \\
\hline $\begin{array}{l}\text { - свыше 30\%ва в нало,З\%). } \\
\text { консолидированного бюджета ЦФО }\end{array}$ & $\begin{array}{l}\text { Владимирская обл., Курская обл. (30,1\%), Тульская } \\
\text { обл. (31,4\%), Белгородская обл. (31,7\%),Тверская обл. } \\
\text { (32,7\%), Липецкая обл. (34,7\%), Костромская обл. } \\
\text { (35,1\%), Брянская обл. (35,4\%), Ивановская обл. (35,5\%), } \\
\text { Воронежская обл. (35,8\%), Орловская обл. (39,5\%), } \\
\text { Тамбовская обл. (40,5\%). }\end{array}$ & 12 \\
\hline
\end{tabular}




\section{Налогообложение физических лиц}

данный налог является бюджетообразующим доходным источником, без которого регионам не обойтись.

Для выяснения обстоятельств сложившегося сокращения удельного веса поступлений налога в 2013-2014гг. необходимо проанализировать факторы, оказывающие влияние на динамику поступлений налога. Значительное влияние на поступление НДФЛ в консолидированный бюджет субъекта РФ оказывают экономические показатели:

- $\quad$ рост производства в регионе отражается на уровне заработной платы занятых граждан, а также на численности экономически активного населения, что, в свою очередь, оказывает обратное влияние на уровень доходов и состояние безработицы в регионе, a, следовательно, динамику поступлений НДФЛ. В данном случае, экономические и социальные факторы тесно связаны между собой, появление последних вытекает из наличия первых, оказывая как положительное, так и отрицательное влияние.

Так, в качестве примера, можно привести сложившуюся ситуацию в Орловской области, когда сокращение числа рабочих мест, отток работающих граждан в мегаполис, привели к тому, что за 2015 год поступления налога на доходы физических лиц в бюджетную систему региона составили 5,718 млрд. рублей, что к плану составляет около 92\%.Таким образом из года в год поступления данного налога продолжают сокращаться, что незамедлительно сказывается на расходной части бюджетной системы региона. [6]

Рассмотрим насколько изменение номинальной заработной платы повлияло на поступление НДФЛ на душу населения в субъектах Центрального федерального округа (таблица 2).

таблица 2

\section{Сопоставление изменений в налоговой базе (номинальная заработная плата) и сумм поступления НДФЛ по субъектам ЦФО}

в 2013-2014 гг. $[4,5]$

\begin{tabular}{|c|c|c|c|c|}
\hline \multirow[b]{2}{*}{ Регионы } & \multicolumn{2}{|c|}{ Номинальная заработная плата, руб. } & \multicolumn{2}{|c|}{ НДФЛ на душу населения, руб. } \\
\hline & $\begin{array}{c}\text { Отклонение } \\
2014 \text { г. к } 2013 \text { г. } \\
\text { (+;-) }\end{array}$ & $\begin{array}{l}\text { темп роста } 2014 \text { г. } \\
\text { к } 2013 \text { г., в \% }\end{array}$ & $\begin{array}{c}\text { Отклонение } \\
2014 \text { г. к } 2013 \text { г. } \\
\text { (+;-) }\end{array}$ & $\begin{array}{c}\text { темп роста } 2014 \text { г. } \\
\text { к } 2013 \text { г., в \% }\end{array}$ \\
\hline РОССИЙСКАЯ ФЕДЕРАЦИЯ & 2703 & 1,09 & 996 & 1,06 \\
\hline \multicolumn{5}{|l|}{ в том числе: } \\
\hline Центральный федеральный округ & 3732 & 1,10 & 2261 & 1,09 \\
\hline Белгородская область & 1674 & 1,08 & 1280 & 1,11 \\
\hline Брянская область & 1937 & 1,10 & 568 & 1,07 \\
\hline Владимирская область & 1654 & 1,08 & 803 & 1,07 \\
\hline Воронежская область & 2176 & 1,10 & 960 & 1,09 \\
\hline Ивановская область & 1610 & 1,08 & 272 & 1,03 \\
\hline Калужская область & 2491 & 1,10 & 1022 & 1,06 \\
\hline Костромская область & 1710 & 1,09 & 848 & 1,09 \\
\hline
\end{tabular}




\section{Налоги и налогообложение 3(141) • 2016}

\begin{tabular}{|c|c|c|c|c|}
\hline \multirow[b]{2}{*}{ Регионы } & \multicolumn{2}{|c|}{ Номинальная заработная плата, руб. } & \multicolumn{2}{|c|}{ НДФЛ на душу населения, руб. } \\
\hline & $\begin{array}{c}\text { Отклонение } \\
2014 \text { г. к } 2013 \text { г. } \\
\text { (+;-) }\end{array}$ & $\begin{array}{c}\text { темп роста } 2014 \text { г. } \\
\text { к } 2013 \text { г., в \% }\end{array}$ & $\begin{array}{c}\text { Отклонение } \\
2014 \text { г. к } 2013 \text { г. } \\
\text { (+;-) }\end{array}$ & $\begin{array}{c}\text { темп роста } 2014 \text { г. } \\
\text { к } 2013 \text { г., в \% }\end{array}$ \\
\hline Курская область & 1865 & 1,09 & 741 & 1,07 \\
\hline Липецкая область & 1742 & 1,08 & 426 & 1,04 \\
\hline Московская область & 2908 & 1,08 & 2056 & 1,10 \\
\hline Орловская область & 1612 & 1,08 & 620 & 1,06 \\
\hline Рязанская область & 2483 & 1,11 & 1026 & 1,09 \\
\hline Смоленская область & 1832 & 1,09 & 203 & 1,02 \\
\hline Тамбовская область & 1701 & 1,09 & 1184 & 1,15 \\
\hline Тверская область & 1416 & 1,06 & 458 & 1,04 \\
\hline Тульская область & 2843 & 1,12 & 1153 & 1,10 \\
\hline Ярославская область & 2431 & 1,11 & 997 & 1,07 \\
\hline г. Москва & 5723 & 1,10 & 4476 & 1,09 \\
\hline
\end{tabular}

Согласно данных таблицы 2 темпы роста поступлений налога на доходы физических лиц в 2014 году к предшествующему году по нескольким субъектам опережают рост налоговой базы по налогу в виде номинальной заработной платы. Это относится к таким субъектам ЦФО, как: Белгородская область - на 0,03\%, Московская область - на 0,02, Тамбовская область - на 0,06\%. В Костромской области темпы роста номинальной заработной платы и поступлений НДФЛ на душу населения абсолютно идентичны. По другим субъектам ЦФО сложилась вполне объяснимая ситуация, когда темпы роста заработной платы (в данном случае налоговой базы по налогу) опережают темпы роста поступлений по данному налогу. Таким образом, от темпов роста заработной платы (доходов физических лиц) зависят темпы поступления в бюджетную систему региона налога на доходы физических лиц.
Другим не менее значимым фактором для решения проблемы увеличения поступлений от НДФЛ выступает численность населения региона и доля работающего населения (экономически активное население страны, которое имеет (или желает иметь) самостоятельный источник средств существования) и которая подпадает под категорию налогоплательщиков НДФЛ.

Среди регионов ЦФО есть субъекты, которые имеют явные конкурентные преимущества для развития ряда производств и создания условий занятости населения и более высокого уровня доходов работающих граждан: Белгородская область и Курская область (добыча металлических руд и производство готовых металлических изделий), Липецкая область (металлургическое производство), Калужская область (производство бытовой техники).

Кроме того, на общем фоне среди регионов ЦФО лидирующие позиции занимает Москва и 


\section{Налогообложение физических лиц}

Московская область, что определяются развитостью в г.Москве торговли $(55,3 \%$ в совокупном выпуске столицы), туризма, воздушного транспорта, а также деятельности, связанной с использованием информационных технологий, науки и научного обслуживания. Город Москва в ЦФО обеспечивает 42,5\% выпуска продукции обрабатывающих отраслей округа.[4]

Имеющиеся преимуществ столицы России и примыкающей к г.Москве Московской области могут обеспечить высокую занятость как своего собственного населения, так и трудовых мигрантов из стран СНГ и близлежащих регионов. Следовательно, такие преимущества предоставляют этим субъектам более выгодные позиции в части поступления налога на доходы физических лиц в бюджетную систему указанных регионов, что подтверждается данными таблиц 1 и 2. Таким образом, миграционная привлекательность Центрального федерального округа определяется диверсифицированной структурой его экономики, выгодным географическим положением, благоприятными климатическими условиями, а также наличием крупнейшего экономического центра в виде Московского мегаполиса с диверсифицированной сферой экономики и развитой социальной инфраструктурой, поэтому на них приходится 85\% миграционного прироста за счет внутренних и внешних передвижений населения. Московская агломерация еще длительный период времени будет готова принимать значительные объемы трудовых мигрантов в свой регион и конкуренция за трудовые ресурсы между Московским регионом и нестоличными субъектами будет только усиливаться.

В сложившихся условиях регионы России, включая субъекты ЦФО, расположенные вблизи мегаполиса, в целях увеличения поступлений от НДФЛ должны развивать собственное производство в регионах, в том числе малый бизнес, обеспечивая занятость и уровень доходов непосредственно на местах. Более низкая заработная плата в субъектах ЦФО подталкивает экономически активное население искать рабочие места в столичном мегаполисе, что обеспечивает им более высокую заработную плату, а региону - необходимый уровень поступлений в НДФЛ в доходы бюджета.

Большое значение на уровень поступлений налога в масштабе Центрального федерального округа оказывает коэффициент вариации денежных доходов на душу населения. Региональный аспект проблемы социального неравенства заключается в наличии многочисленных барьеров для межрегиональной миграции и выравнивания заработной платы в различных регионах, что определяет возникновение депрессивных регионов, неспособных обеспечить нормальный уровень доходов населения и их рост пропорционально общероссийскому.

Так, согласно данных Росстата, размер номинальной заработной платы в регионах ЦФО за 2014 год варьирует от 20 тыс. рублей (Брянская, Ивановская, Костромская, Орловская и Тамбовская области) до 38,6 тыс.рублей (Московская область) и до 61,2 тыс.рублей (г.Москва),что подтверждает отмеченные факты о значительной вариации заработной платы: в 1,9 раза относительно Московской области и в 3 раза относительно г.Москва.[4]

Руководители регионов России, включая Центральный федеральный округ, не должны допускать сокращения производств как крупных областных предприятий, так и сужения сферы действия субъектов малого бизнеса и увольнения персонала в этих организациях, а также должны быть заинтересованы в росте доходов населения обслуживаемых территорий из различных источников, что определяет уровень поступлений налога на доходы физических лиц в бюджетную систему региона, как одного из основных бюджетообразующих налогов региональных бюджетов России.

В сложившихся кризисных условиях региональным органам власти следует уделять особое внимание поступлению налога на доходы физических лиц и особенностям его администрирования, что можно рассматривать в качестве стимула разрешения назревших вопросов региональной экономики субъектов российской Федерации. 


\section{Налоги и налогообложение 3(141) • 2016}

\section{Библиография}

1. Налоговый кодекс РФ, Глава 23.

2. Бюджетный кодекс РФ

3. Журавлева Т.А., Филиппов Р.А. Основные проблемы субъектов ЦФО по поступлению налога на доходы физических лиц в бюджеты регионов//Финансовый анализ и аудит.-2010.-№4.-С.8-10.

4. Официальный сайт Федеральной службы государственной статистики РФ-www.gks.ru

5. Официальный сайт Федеральной налоговой службы РФ-www.nalog.ru

6. В Орловской области сбор НДФЛ не достиг уровня 2014 года //Орловские новости.-2016, от 20.01http://newsorel.ru/

7. Казьмин А.Г., Оробинская И.В. Анализ поступления налогов в бюджеты областей ЦентральноЧерноземного района // Финансы и управление. - 2012. - 1. - С. 156 - 211. URL: http://www.e-notabene. ru/flc/article_358.html

\section{References (transliterated)}

1. Nalogovyi kodeks RF, Glava 23.

2. Byudzhetnyi kodeks RF

3. Zhuravleva T.A., Filippov R.A. Osnovnye problemy sub"ektov TsFO po postupleniyu naloga na dokhody fizicheskikh lits v byudzhety regionov//Finansovyi analiz i audit.-2010.-№4.-S.8-10.

4. Ofitsial'nyi sait Federal'noi sluzhby gosudarstvennoi statistiki RF-www.gks.ru

5. Ofitsial'nyi sait Federal'noi nalogovoi sluzhby RF-www.nalog.ru

6. V Orlovskoi oblasti sbor NDFL ne dostig urovnya 2014 goda //Orlovskie novosti.-2016, ot 20.01-http:// newsorel.ru/

7. Kaz'min A.G., Orobinskaya I.V. Analiz postupleniya nalogov v byudzhety oblastei Tsentral'noChernozemnogo raiona // Finansy i upravlenie. - 2012. - 1. - C. 156 - 211. URL: http://www.e-notabene. ru/flc/article_358.html 